\title{
The Social Transformation of Coffee Houses: The Emergence of Chain Establishments and the Private Nature of Usage
}

\author{
Rachael A. Woldoff ${ }^{1}$, Dawn Marie Lozzi ${ }^{1}, \&$ Lisa M. Dilks ${ }^{1}$ \\ ${ }^{1}$ Department of Sociology and Anthropology, West Virginia University, Morgantown, West Virginia \\ Correspondence: Rachael A. Woldoff, Department of Sociology and Anthropology, West Virginia University, PO \\ Box 6326, 307 Knapp Hall, Morgantown WV, 26506-6326, USA. Tel: 1-304-293-8831. E-mail: \\ rachael.woldoff@mail.wvu.edu.
}

\author{
Received: March 12, 2013 Accepted: March 26, 2013 Available online: August 13, 2013 \\ doi:10.11114/ijsss.v1i2.200 URL: http://dx.doi.org/10.11114/ijsss.v1i2.200
}

\begin{abstract}
Ray Oldenburg (1989) developed the concept of third places as environments that offer friendship and a sense of community. However, the idealized image of the coffee house may need revision. In recent decades coffee houses have transformed from small-scale businesses to corporate-owned franchises, and with the advent of personal electronic devices many people now use them to work rather than to socialize. Using unobtrusive observation data from three independently-owned and three chain-based coffee houses in the Boston area, this research examines the ways in which modern coffee houses live up to or defy Oldenburg's social expectations of a third place. Two key findings reveal that: 1) people increasingly use coffee houses as both a social sphere and a private zone to work, read, and use electronic devices; and 2) chain coffee houses, though often criticized for their sanitized lack of character, may better meet customers' new third place needs by providing a wider variety of amenities (e.g., types of seating, food, and media) and free services that are in high demand (e.g., Wi-Fi).
\end{abstract}

Keywords: third place, urban spaces, public spaces, coffee house, café, neighborhoods

\section{Introduction}

Researchers have long been fascinated with public spaces and the meanings they hold for individuals and communities (Goffman, 1959, 1963, 1971; Lofland, 1973). In particular, sociologists have celebrated coffee houses as "third places" that promote friendship and community while serving as an alternative to socialization at home and work (Oldenburg, 1989). However, coffee houses vary in the extent to which they fulfill these functions. Furthermore, two major transformations in the form and function of coffee houses may affect their utility as third places.

First, there has been a shift in coffee house usage and culture from people using them primarily as public places for socialization to using them as shared spaces for work and productivity. The notion of the café as an environment to foster geniality and communication stems from a larger discourse about the functions of public places for cities (Whyte, 1988; Zukin, 2010). Historically, urban researchers have asserted that coffee houses serve as ideal spaces for people to speak freely about political and social concerns (Cowan, 2004; Oldenburg, 1989; Pincus, 1995), but with the rise of portable electronic devices and telecommuting, an increasing number of people now use coffee houses less for socializing and more as a hub for reading, working, and productivity (Bazelon, 2009).

A second significant transformation is associated with ownership. The transition from small, locally-owned coffee houses to chain-owned cafés has been well documented (Zukin, 2010). The popular image of a bohemian coffee house includes a devaluation of uniformity as illustrated by casual, artistic, or shabby furnishings and a lack of emphasis on branding. This lack of homogeneity often extends to employees' attitudes, behaviors, and appearance, as well as to the coffee and food (Oldenburg, 2001). In theory, residents should be more likely to support locally-owned businesses as a way of giving back to the community (Mohr, Webb, \& Harris, 2001). Chain coffee shops, in contrast, are associated with corporate standards of cleanliness, bland simplicity, and prominent branding. Chain customers are stereotyped as having a low commitment to creative endeavors and desirous of upscale environments without regard for aesthetic distinctiveness, cultural motifs, and the details of how and why a coffee house runs the way it does (Roseberry, 1996). Furthermore, owners of chain businesses view the local community as an afterthought, failing to prioritize the interests of the residents they serve and thereby undermining the cafe's 
traditional role as a place that nourishes community (Clark, 2007; Porter, 1995; Thompson \& Arsel, 2004).

We qualitatively address these transformations in the form and function of coffee houses using Oldenburg's (1989) concept of a third place. Two major questions guide our research. First, in the era of portable technology, to what extent do coffee houses serve the social purpose of a third place? Through systematic observation of the spaces, customers, and activities, we evaluate Oldenburg's assertion that coffee houses are the sociable bases of communities. Second, in what ways do independently-owned and chain-based coffee houses differ? Through comparison, we challenge the assumed differences in the social roles of these establishments.

\subsection{Coffee Houses as Third Places}

Oldenburg (1989) forwarded the concept of the "third place," as one of three categories of places where people spend their time. Home is the first place, a "domestic environment" for relaxation, but where hosting social events involves work and cost, decreasing its desirability for socializing. Second places are designated for "gainful or productive work." The third place is "inclusively sociable, offering both the basis of community and the celebration of it" (14). According to Oldenburg, cafés epitomize third places because they promote friendship and a sense of community, while also fulfilling the human need for novelty that first and second places do not; it is here that individuals can escape boredom and interrupt their mundane routines.

Yet recent research suggests a shift in coffee house usage and culture. According to Hampton and Gupta (2008), Wi-Fi (i.e., wireless high-speed Internet technology) has significantly impacted café social life. Although urban public places are celebrated for their power to draw like-minded people and stimulate social ties, many customers now hide behind "protective shields" (e.g., laptops, E-readers, and iPods). Lee (2007) noted that many self-employed people patronize coffee houses because they provide a sense of community to those who can work from anywhere (e.g., freelance writers and programmers) or to those who seek to separate themselves from "typical corporate farms." Blank and Van Vooren (2007) examined café patrons who "camp out" or stay for long periods of time (i.e., between three to five hours) and found that "campers" did so to get away from the hustle and bustle of everyday life and gain alone time rather than to engage in socialization. Similarly, student customers told Waxman (2006:47) that they preferred working in coffee houses to avoid "a sterile library atmosphere." This research is in stark contrast to Oldenburg's idealized view of a third place as a "unifunctional" space to be used strictly for socializing, and his assertion that those who conduct work in these environments "erode the fabric of society" (1989:215). In accordance with this view, some workers at some independent coffee houses have engaged in a backlash against the use of electronic devices, actually restricting their use and claiming that they turn relaxing cafés into cubicles (Heffernan, 2011).

Aside from technology, the rise of corporate chains has presented challenges for third places. Zukin (2010) discussed the loss of authenticity and community in public spaces, specifically distinguishing cafés that are independently-owned from those that are chain-based. As corporate coffee houses have become more ubiquitous and a larger cross-section of people frequents such establishments, there is reason to believe that the line between independent and corporate places has blurred, such that neighborhood residents may view their local Starbucks as the community's coffee house.

The purpose of this research is to expand our understanding of coffee houses as third places. We conducted a qualitative case study of three independently-owned and three chain-based cafés in the Boston area and documented the atmospheres, customers and activities taking place. Specifically, we aimed to explore 1) whether coffee houses still serve the social function of a third place despite the increasing popularity of portable technology; and 2) the ways in which independently-owned and chain-based coffee houses differ.

\section{Methods}

Coffee houses in Boston gained popularity as social institutions after World War I. The passage of the $18^{\text {th }}$ Amendment outlawing the manufacture and sale of alcohol made cafés a replacement for bars as meeting sites (Pendergrast, 1999). But between the 1950s and the 1980s coffee houses declined because of inflation, job losses, war, and a rise in coffee prices (Chadios, 2005). However, coffee houses bounced back in the late 1980s when Starbucks transformed from a locally-owned storefront to a corporate giant (Clark, 2007). During this time, the Boston City Council attempted to reestablish city centers for social, economic, and cultural life, and coffee houses began to appear in city squares (Chadios, 2005). Boston is known as a city in which residents have exceptionally high coffee consumption. In 2010, one in three people reported that they "need" coffee on a daily basis, and 17\% said they drank four or more cups every day (PRWEB, 2010). Research from the Boston campus of the University of Massachusetts found that Bostonians ingest one thousand pounds of pure caffeine every day (Clark, 2007). We gathered data using unobtrusive observation from three independently-owned and three chain-based coffee houses in the Greater Boston area. Qualitative observation is ideally suited to studying 
different social worlds because immersion in the field enables researchers to better understand how individuals interact with their real surroundings (Lindesmith, Strauss, \& Denzin, 1975).

\subsection{Selection of Neighborhoods}

We chose three geographically distinct neighborhoods to conduct observations based on the availability of both independently-owned and chain-based coffee houses in close proximity. Preliminary observations narrowed the choice of sites to three café pairs in Copley Square, Davis Square, and Central Square. These locations share common population characteristics, spatial proximity to major public transportation lines, and similar architectural features, making them ideal for comparison.

\subsubsection{Copley Square}

Copley Square is a public square in the Back Bay neighborhood near the central business district in downtown Boston. It is composed of 9,346 residents, who are primarily young and renters (Table 1). The relatively low neighborhood median age of 22 is likely due to the universities located in the area (e.g., Boston University and Northeastern University). Copley Square Plaza sits in the middle of the neighborhood, as do the Copley Massachusetts Bay Transit Authority train stop and numerous bus stops. Moving away from the center, one finds the Boston City Library and a number of retail stores, restaurants, high-end hotels, and shopping malls. This ring also contains both coffee houses used for observations.

\subsubsection{Davis Square}

Davis Square is located in Somerville, near the city line of Cambridge and five miles southeast of Copley Square. It comprises 3,139 residents, many of whom are relatively young and live in owner-occupied housing units. The median age for this neighborhood is higher than Copley Square at 31 years of age, but still rather young compared to surrounding Middlesex County (Table 1). Davis Square merges the historic atmosphere of Boston with newer facilities like movie theaters, underground train stations, and renovated buildings and is the connecting point for three of the community's main streets. This junction contains a brick plaza that commuters commonly use as a waiting area for buses or carpools. The two coffee houses observed here were directly across the street from one another.

\subsubsection{Central Square}

Central Square is located on the very busy and populous Massachusetts Avenue in Cambridge. Most of the 5,246 individuals who live here are relatively young and many reside in owner-occupied housing units. The median age for this neighborhood is about the same as Copley Square at 25 (Table 1). The area is culturally diverse, with eateries and retail stores that cater to various nationalities (e.g., Greek, Korean, Italian, Middle Eastern, Tibetan, Portuguese, Mexican, and Arabic). Similar to the other locations, this community is a hub for public transportation.

Table 1. Community Characteristics

\begin{tabular}{|c|c|c|c|c|c|c|c|c|}
\hline & \multicolumn{2}{|c|}{ Davis Square } & \multicolumn{2}{|c|}{ Central Square } & \multicolumn{2}{|c|}{ Copley Square } & \multirow{2}{*}{$\begin{array}{c}\text { Consolidated } \\
\text { Metropolitan } \\
\text { Statistical } \\
\text { Area }\end{array}$} & \multirow{2}{*}{$\begin{array}{l}\text { United } \\
\text { States }\end{array}$} \\
\hline & $\begin{array}{l}\text { Tract } \\
3509\end{array}$ & $\begin{array}{l}\text { Middlesex } \\
\text { County }\end{array}$ & $\begin{array}{l}\text { Tract } \\
3537\end{array}$ & $\begin{array}{l}\text { Middlesex } \\
\text { County }\end{array}$ & $\begin{array}{c}\text { Tract } \\
104.01\end{array}$ & $\begin{array}{l}\text { Suffolk } \\
\text { County }\end{array}$ & & \\
\hline Total population & 3,139 & $1,465,396$ & 5,246 & $1,465,396$ & 9,346 & 689,807 & $3,406,829$ & $281,421,906$ \\
\hline \multicolumn{9}{|l|}{ Population averages } \\
\hline Median household income & 54,779 & 60,821 & 42,178 & 60,821 & 26,576 & 39,355 & 55,183 & 41,994 \\
\hline Average household size & 2.1 & 2.5 & 1.7 & 2.5 & 1.8 & 2.3 & 2.5 & 2.6 \\
\hline Median age & 30.8 & 36.4 & 24.6 & 36.4 & 22.4 & 31.7 & 36.3 & 35.3 \\
\hline \multicolumn{9}{|l|}{ Population percentages } \\
\hline Female & 53.3 & 51.6 & 50.3 & 51.6 & 49.3 & 51.8 & 51.9 & 50.9 \\
\hline White & 88.1 & 85.9 & 75.8 & 85.9 & 72.4 & 57.8 & 82.5 & 75.1 \\
\hline Black & 2.3 & 3.4 & 4.5 & 3.4 & 7.1 & 22.2 & 7.0 & 12.3 \\
\hline Asian & 6.1 & 6.3 & 13.3 & 6.3 & 13.4 & 7.0 & 4.9 & 3.6 \\
\hline Hispanic/ Latino & 3.4 & 4.6 & 6.3 & 4.6 & 7.4 & 15.5 & 5.9 & 12.5 \\
\hline Owner-occupied housing & 30.0 & 61.7 & 24.4 & 61.7 & 10.1 & 33.9 & 59.0 & 66.2 \\
\hline High school degree or higher & 92.0 & 88.5 & 96 & 88.5 & 91.3 & 78.1 & 24.8 & 80.4 \\
\hline Bachelor's degree or higher & 65.4 & 43.6 & 75.4 & 43.6 & 65.3 & 32.5 & 22.6 & 24.4 \\
\hline $\begin{array}{l}\text { Enrolled in college } \\
\text { or graduate school }\end{array}$ & 29.6 & 20.1 & 74.5 & 20.1 & 85.4 & 43.5 & 30.8 & 22.8 \\
\hline
\end{tabular}

Description: Data based on the 2000 US Census. Consolidated Metropolitan Statistical Area as defined by the Census includes the Greater Boston communities, the North Shore communities, South Shore communities, and communities just over the New Hampshire border. 


\subsection{Selection of Coffee Houses}

Using purposive sampling and preliminary observations, we first selected three independently-owned coffee houses and then paired them to a Starbucks in the same neighborhood. To qualify for the study, each café had to serve coffee and tea as well as light food options and had to have seating and space to socialize and spend time. Coffee houses were excluded if they only catered to carry out or mainly served meals and had wait staff. If multiple Starbucks businesses existed in the vicinity of the independent coffee house, we chose the one that best fit the criteria of inclusion. The following coffee houses were used in this study: 1) Copley Square: Pavement Coffee House compared to a Starbucks a few blocks away; 2) Central Square: 1369 Coffee House compared to a Starbucks down the street; and 3) Davis Square: Diesel Café compared to a Starbucks across the street.

\subsection{Procedures}

Unobtrusive observation allows individuals under study to continue their normal activities as if they were not under a researcher's examination, thereby creating higher internal validity (Emerson, 1981). In addition, this method permits the recording and analysis of information in "real time," such that observations more accurately represent the features of the site (Hammersley, 1987). Each café was visited on three different occasions--morning or early afternoon, mid-afternoon, and evening--for one to three hours on each visit. The time of day for the observations varied in order to document the extent to which the crowd and activities changed over the course of the day (i.e., commuters in the morning and regulars in the evening may behave differently). Using a laptop to record the observations, the coding sheets and field notes focused on five coffee house features: 1) patrons' and employees' levels of sociability; 2) seating characteristics; 3) content of activities; 4) amenities; and 5) atmosphere. We used open coding to categorize the data and establish themes (Corbin \& Strauss, 2008).

\subsubsection{Sociability}

Oldenburg (1989:61-62) writes: "What urban life increasingly fails to provide, and what is so much missed, is convenient and open-ended socializing--places where individuals can go without aim or arrangement and be greeted by people who know them." Oldenburg's concept of a third place not only emphasizes the importance of sociability, but also requires the café environment to be welcoming. Individuals must not be afraid of exclusionary behavior from regulars in cliques. Our field notes document how employees treat regulars or "insiders" versus new patrons or "outsiders" and the types of interactions among customers.

\subsubsection{Seating}

Oldenburg believes that seating is the second most important factor in a successful third place. Seating encourages socializing when it is arranged in a way that allows strangers to sit next to each other. Close seating is especially desirable as it allows people to overhear conversations that sound interesting and join them. Thoughtful seating arrangements can also help control crowding and environmental noise as spaces with larger tables tend to have higher noise levels and those with smaller tables promote quiet, intimate conversations. Our field notes focus on the presence and arrangement of sofas, tables, bars, booths, and "cubbies" or workstations, and detail the locations of windows, room dividers, and barista stations.

\subsubsection{Activities}

Oldenburg asserts that in a true third place, conversation should be the only activity. However, we focus on three main activities at each coffee house: socializing, working, and leisure. We coded patrons as "socializing" if they were talking to someone else or interacting with the baristas beyond ordering coffee or food (e.g., discussing weekend plans, shared acquaintances, or hobbies and interests). Patrons were "working" if they were reading textbooks, writing with a pen or pencil, or typing on computers. Lastly, some patrons engaged in "leisure" activities such as reading, knitting, or people watching.

We also noted the customer types who visited each location, first by distinguishing between loners working or else engaged in leisure (i.e., sitting alone with a beverage or snack, while reading the newspaper, a book, E-reader, or knitting) and customers in groups (i.e., social groups talking to one another in semi-private conversations or working together on school-related work and non-social groups working separately at the same table, but not socializing).

\subsubsection{Amenities}

According to Oldenburg, people who live in suburban areas use their large homes and the amenities they offer to retreat from the community. However, if third places offered the same amenities or more, people may become more interested in using public third places again and may actually prefer to spend time there. We recorded the various amenities that different coffee houses offered, such as Wi-Fi, newspapers, bulletin boards, power outlets, 
and time limits on services or stays.

\subsubsection{Atmosphere}

The atmosphere at a third place should be inviting, relaxed, and playful. Oldenburg (1989:38) believes that third places are the areas where "joy and acceptance should reign over anxiety and alienation." A coding sheet measured the atmosphere at each location by noting the type and volume of music, volume of chatter, wall color, lighting, and décor, all important elements for a welcoming environment.

\subsubsection{Additional Information}

In addition to observational data, we collected documents (e.g., business cards, fliers, frequent shopper cards, and website documentation) and took photographs to better understand each coffee house. Photos are an important aspect of observational research because they assist in vivid description and free the researchers to pay attention in real time to the activities in the space. Photos of seating, people, bulletin boards, websites, and signage also convey what the owners of the coffee houses seek to communicate to patrons and the outside world.

\section{Results}

Field notes were dissected and categorized to discover themes and motifs about third places (Giorgi, 1997; Strauss \& Corbin, 1990). Our findings are organized according to each research question.

\subsection{In the era of portable technology, do coffee houses still serve the social purpose of a third place?}

To help understand if coffee houses still serve the social purpose that Oldenburg (1989) conceptualized, the six cafés are divided into three groups: social spaces (people mostly socializing and not using electronics), multifunctional spaces (people both socializing and using electronics), and non-social spaces (people mostly not socializing because of the use of electronics). The resultant groups are as follows: 1) social spaces: Starbucks, Central Square; 2) multifunctional spaces: Pavement Coffee House, Copley Square; Diesel Café and Starbucks, Davis Square; Starbucks, Copley Square; and 3) non-social spaces: 1369 Coffee House, Central Square.

\subsubsection{Social Spaces}

The Central Square Starbucks conforms most closely to Oldenburg's vision of a "celebration of the community," a place where individuals enrich public life, encourage sociability, and promote companionship in a relaxing and informal environment (Figure 1). The majority of people who patronized this location appeared to be there for the purpose of conversation, whether with people they knew or not. For example, on one visit a couple sat in the middle of the crowd conversing and enjoying their beverages; during another observation, two middle-aged women enjoyed a light-hearted conversation with an occasional burst of laughter.

The small size of this Starbucks may have encouraged the high level of socializing. During every observation period, all seats were occupied. This location was especially crowded during high-traffic times, which coincided with the workday rush hour. People continued to carry on conversations, even while standing and waiting for table space.

Although it had all the standard amenities Starbucks' customers expect (e.g., free Wi-Fi and newspapers for sale), work was not the dominant activity. Only a small number of individuals were using personal technology, and it appeared that the bar seating was reserved especially for them because of the numerous power outlets located there. Even so, it was often the case that the majority of the people at the bar were facing each other and conversing rather than working. Of the two people using computers during the second observation, one was checking email and the other had on headphones and was working on a music-editing program. The only other person using an electronic device was a woman talking on her cell phone.

There were also a number of people at this location for leisure. During two observation periods a few patrons sat drinking their beverages and reading newspapers and paperbacks (Figure 2). For example, a man sat by himself and was so engaged in reading a book that when he went to pick up his drink he almost knocked it over. In the same period, another man reading a newspaper seemed frustrated at the small size of the tables because at one point he put his beverage on the floor so he could lay out the full paper.

This Starbucks had a distinguishing feature that no other coffee house in this study had: friendly baristas. It was clear that the baristas were on a first-name basis with many of the customers, were familiar with their regular orders, and knew significant personal information about them. During the second observation, one customer spoke with a barista about her newborn baby, telling him about the baby's milestones and sharing pictures. On another occasion, a customer had a long conversation with the barista about mutual friends and weekend plans. 


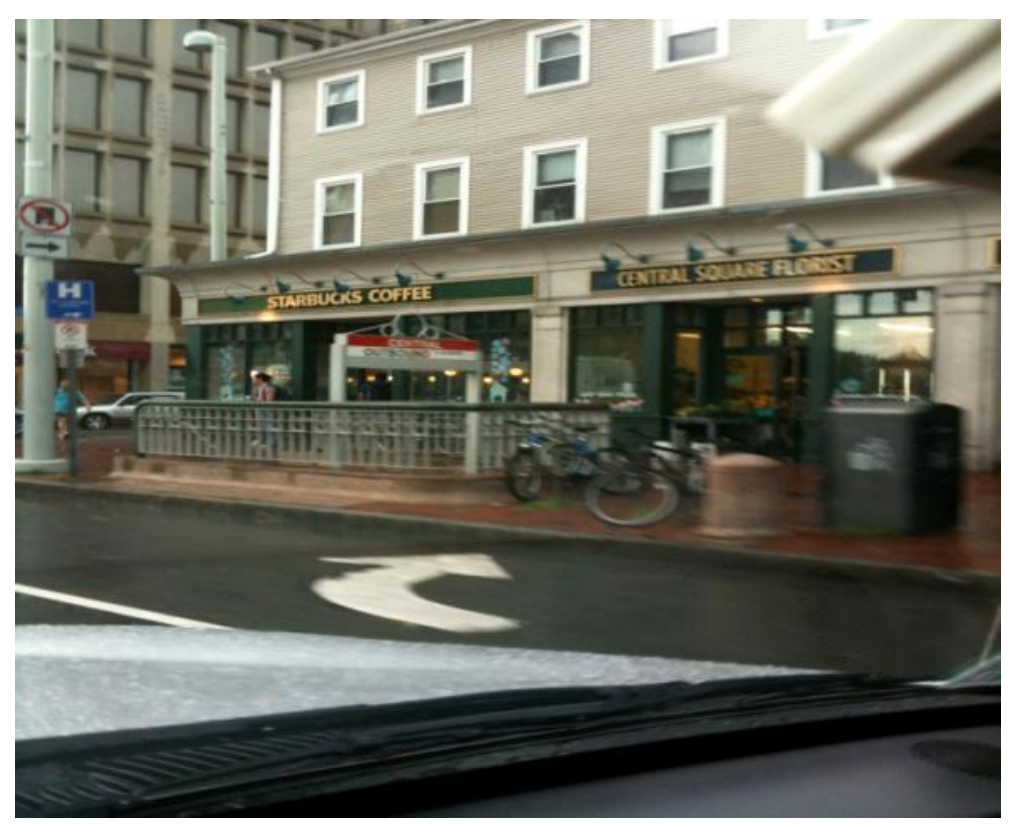

Figure 1. Outside Central Square Starbucks

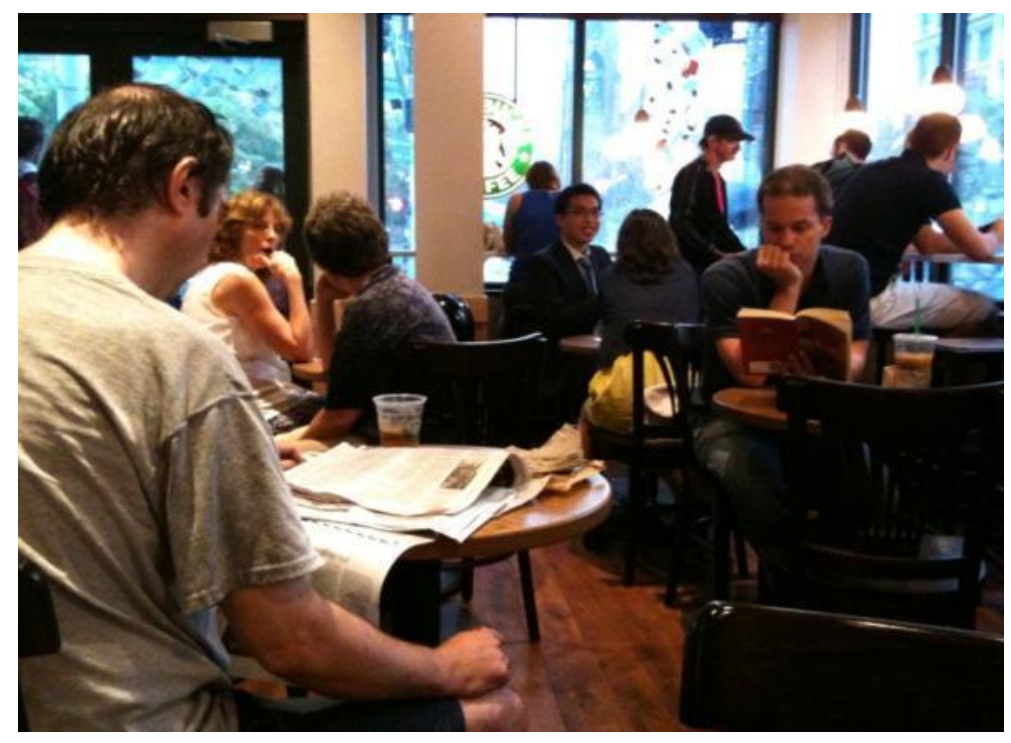

Figure 2. Inside Central Square Starbucks

\subsubsection{Multifunctional Spaces}

The majority of coffee houses in this study are classified as multifunctional spaces. Although they are used as a traditional third place for socializing and community, these cafés include a large number of individuals engaged in productive work. According to Oldenburg (1989) such a multifunctional space is a "hostile habitat" that actually harms socializing because productivity dominates social activities. However, our observations suggest that this view may be overstated. Socializing was still a large part of each multifunctional space with both small and large groups engaging in conversation.

Pavement Coffee House is an independently-owned coffee house in Copley Square (Figure 3) and is the first example of a multifunctional space. This café is a large space with no shortage of seating and is separated into many smaller sections by wall dividers that create small "living rooms" with couches, armchairs, and coffee tables, all designed to foster socializing. Oldenburg describes these sections as rooms similar to those in the home, where friends can get together to socialize, but where nobody has to play host. The individuals in these areas sat back in the armchairs, sat closely with one another on the couch, or spoke quietly in semi-private sections. For example, one group talked about their summer plans while another recounted a story about a wedding they attended. Rarely did patrons at this location work on computers alone and on only one or two 
occasions did a single individual claim a large amount of space, covering the table with papers, computers, or notebooks (Figure 4).

The Berkley School of Music campus is located within this neighborhood, which keeps this coffee house filled with students working on computers, reading textbooks, and using the large tables for study group sessions. Students also socialize with their professors here. During the first observation, a large group sat at the long table in the center of the café focused on a study guide and textbook. Even though the majority of students were completing school-related work, they were also conversing on a regular basis, often about their studies.

Pavement offered customers very few work-related amenities, which contributed to multifunctionality. There were a small number of power outlets for laptops, and especially notable was the four-hour daily limit on Wi-Fi, bluntly posted on the walls and at tables. Newspapers and other sources of media were not available for sale. People who wanted to work usually congregated at the computer bar area, which seats five and has a few power outlets. During the observation sessions the bar was completely occupied by patrons who seemed to be working on computers, some who were working together.

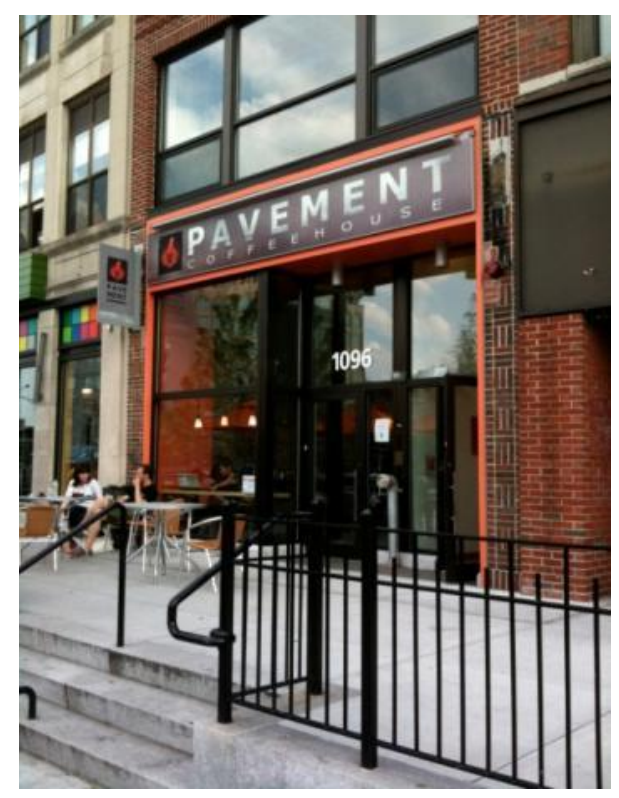

Figure 3. Outside Pavement Coffee House

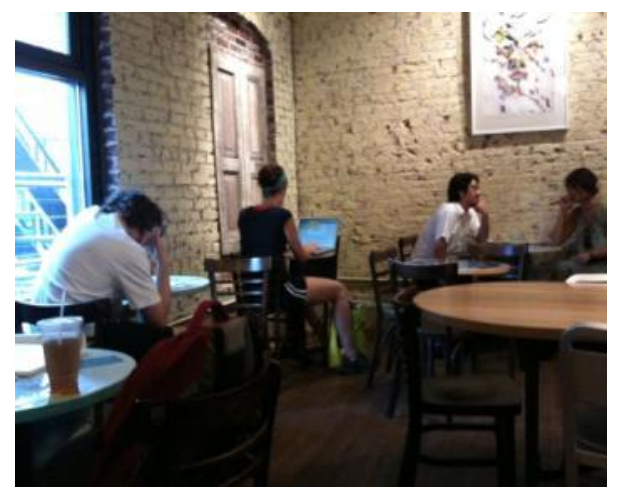

Figure 4. Inside Pavement Coffee House

While Oldenburg might not consider Diesel Café in Davis Square a successful third place, as the second multifunctional coffee house in our study, its combination of sociability and productivity may represent the new model of a third place. Although Diesel fostered socializing, it was also a place where people frequently worked alone and engaged in "loner" leisure (e.g., knitting by the natural light or reading a book) (Figure 5).

The entrance to Diesel had several metal chairs and tables for working or socializing in the natural light that comes through the large glass-paneled garage doors. The second room in Diesel had a bar, two pool tables, and a black and white photo booth (Figure 6). During the day the bar is completely occupied by patrons on computers, utilizing the nearby power outlets. Davis Square is also adjacent to a university campus, which explains the large 
groups of students reading textbooks, writing in notebooks, and typing on computers. The two most common applications opened on laptops were word processing programs and email accounts. Other lone individuals working on computers or eating occupied booths along the opposite side of the room. The back section of Diesel provided a quieter environment. During the first observation period, this section was filled with couples sitting in booths chatting about personal matters and catching up on gossip. Loners also enjoyed the quiet for reading for leisure and work. For example, a man was sitting at a table for two, leaning on an elbow concentrating on the book he was reading, while another man was curled up against the side of a booth reading a hardcover textbook.

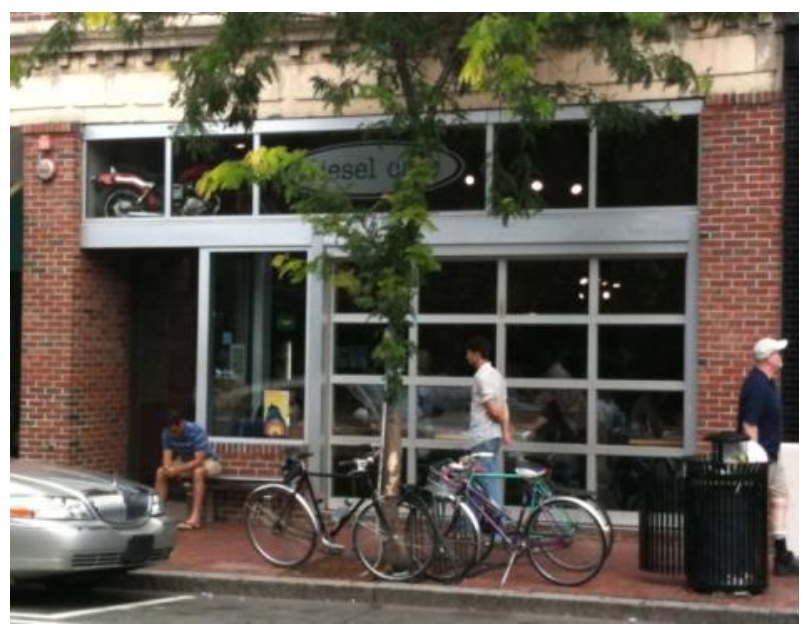

Figure 5. Outside Diesel Café

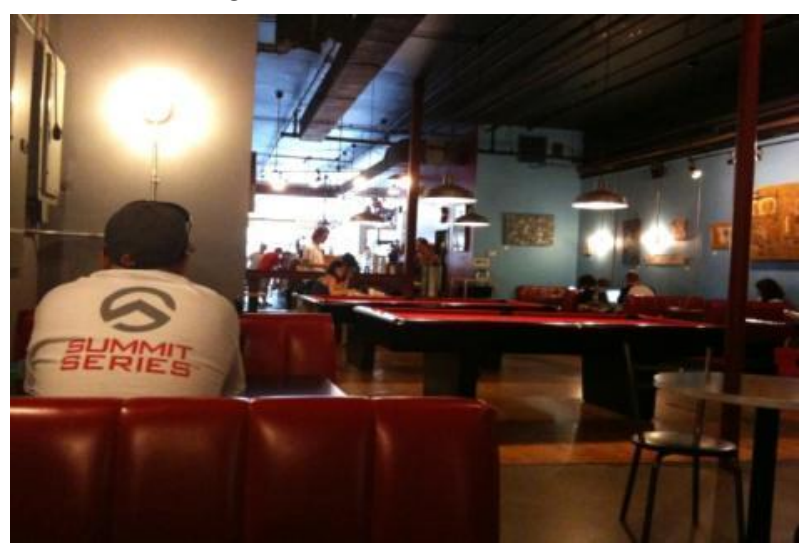

Figure 6. Inside Diesel Café

The Starbucks at Davis Square is another example of the multifunctional third place (Figure 7). The seating area made this location ideal for multiple functions. The barista station was separated from the rest of the establishment by an extremely large table that easily sat 30 and was largely full during all observations. Seating at the front of the café featured a gas fireplace that was exposed on each side, overstuffed chairs, and a small table. Behind these chairs was a table that could seat four to six people. Moving closer to the windows was a row of small tables that could seat two, though one person with a computer, books, and bags usually claimed these tables. Lastly, this coffee house had a bar set up against the windows that extended the whole length of the café from the front door, around the bend, to the back door where loners sat.

A few customers were at the Davis Square Starbucks to socialize and leisurely read books by the fireplace, but in general, the activities at this location centered on the use of personal electronic devices. All but a few patrons were focused on working and most refrained from speaking to others, often listening to headphones (Figure 8). Many patrons worked on laptops, and this location lacked both small and large groups, which may have contributed to the quiet atmosphere. An uncommon characteristic of this Starbucks was that loners mostly occupied the large communal table, which seemed intended for socializing even though this did not often occur. The exceptions to electronic device use were a couple sitting in the corner at a table for two, dressed in business attire, socializing, and writing memos in portfolios, another customer in the middle of the large table enjoying a cup of coffee and a pastry, and a different customer reading a book on an overstuffed chair by the fireplace. 


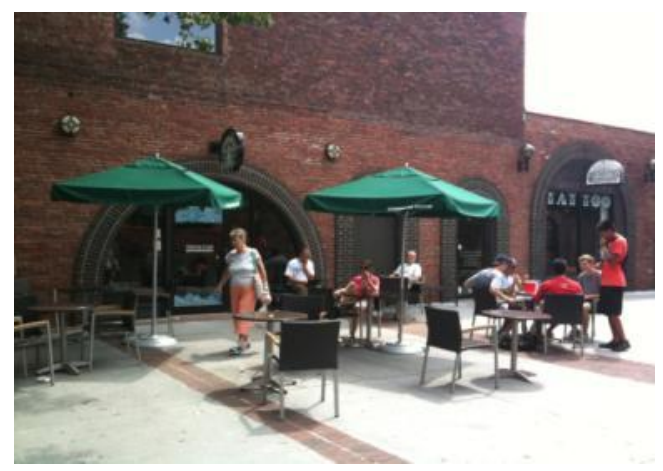

Figure 7. Outside Davis Square Starbucks

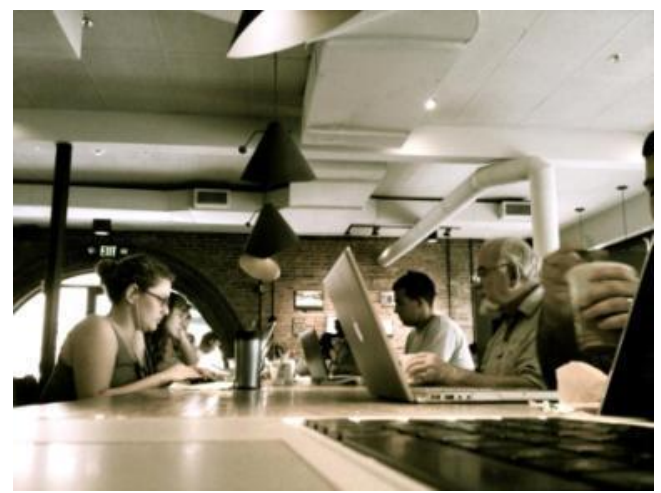

Figure 8. Inside Davis Square Starbucks

The Starbucks at Copley Square, a long, narrow establishment, was the busiest and largest of the three Starbucks locations (Figure 9), but was the most accommodating to the needs of workers. It was far from what Oldenburg idealized as a third place. Most people were working alone with computer screens opened to word processing programs, spread sheets, and email accounts. These individuals usually sat at small tables meant for two, a freestanding bar with stools, or on the couch at the front of the establishment, often claiming as much space as possible. For instance, on one occasion a woman claimed the whole couch to herself. Still, socializing occurred at this Starbucks, with small groups conversing at two-person tables or around the large communal table. On one observation, a sizeable group of regulars sat at the large table collaborating on a variety of tasks, including overcoming computer problems.

It is important to note that this café changed radically across our observation periods such that the seating was completely different on the second visit. The owner removed most of the small tables and a large table that seated twelve and installed individual seating arrangements called "cubbies" (Figure 10). These cubbies were arranged side-by-side in groups of five to nine with built-in seating and hooks for bags and jackets. This change in seating suggests that, at least at this Starbucks, the owners were adapting to the increased use of computers. In fact, during one observation all the cubbies were occupied while the couches were vacant, signifying cubbies as the preferred seating choice.

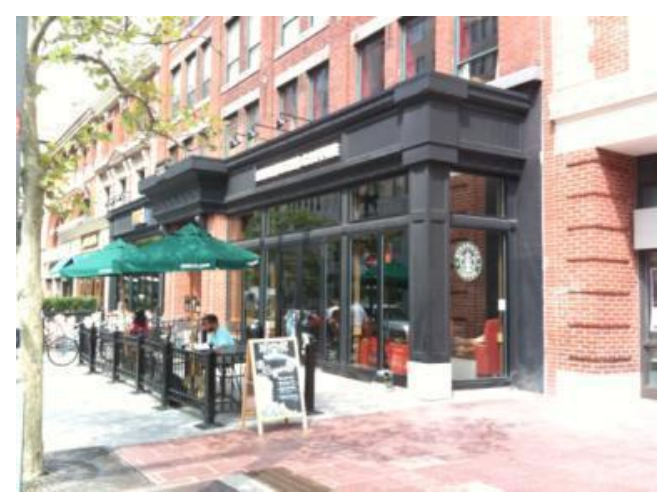

Figure 9. Outside Copley Square Starbucks 


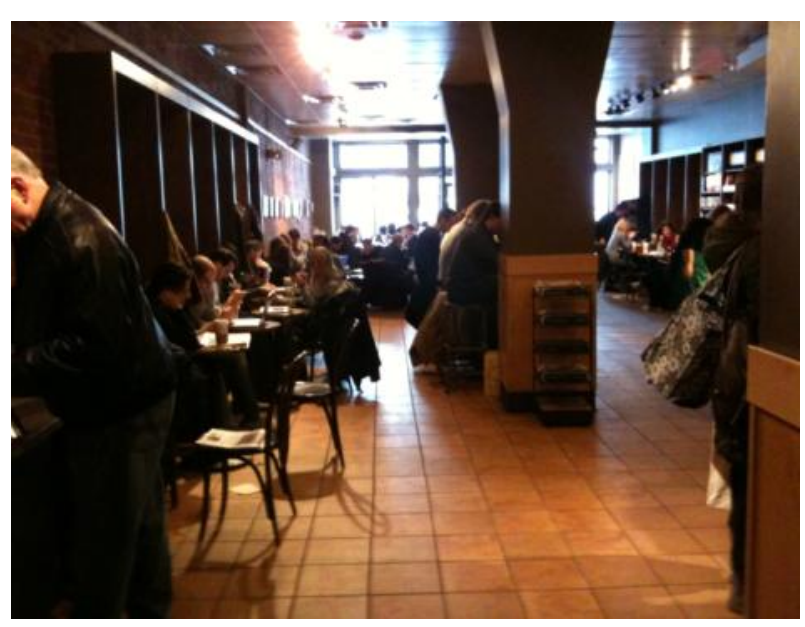

Figure 10. Inside Copley Square Starbucks

\subsubsection{Non-social Spaces}

Interestingly, 1369 Coffee House's website explicitly states that its goal is to be a "third place" for customers, and it was the only café to use this language (Figure 11). In accordance with Oldenburg's conceptualization, the building has the exterior structure of a home residence, is designed and decorated inside in the style of a person's home, having the character, personality, and authenticity of a third place coffee house. But despite its third place appearance, this coffee house lacked the celebration of socializing and community that Oldenburg discusses. Rather, to the extent it was used, it was a non-social space where individuals focused on being productive or reading rather than social.

Although the two front window seats let in ample light, the walls were dark and the lack of artificial lighting gave the space a cavernous feel (Figure 12). A long hallway lined with tables and chairs led to a large table that could easily seat 15 . But the lack of space was visibly uncomfortable for patrons who were crowded into small chairs and tables. In addition, the service line crowded the tables at the front of the coffee house, and the only place to work without the worry of a computer being knocked over was in the back at the large table. Patrons on the way to the restroom constantly bumped into the customers using the hallway seating.

Very few people patronized this café. This location was ideal for getting coffee to go, but it was difficult to work because of the cramped seating arrangements and the lack of free Wi-Fi. During the first observation, a college-aged woman worked diligently on her computer and an older woman sat at the window table reading a book. Customers were not permitted to stay for long periods of time per order of the signs mentioning a 30-minute loitering limit. The reason for this limit could be that the shop owners did not want to attract homeless people, a problem in this area, or because the café was so small that the owners wanted to cater to people who were eating and drinking rather than working and claiming seating and table space, which were at a premium.

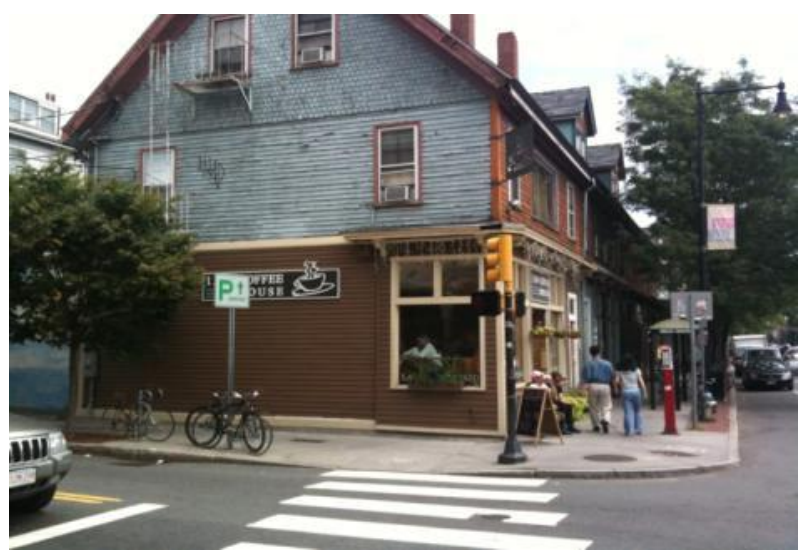

Figure 11. Outside 1369 Coffee House 


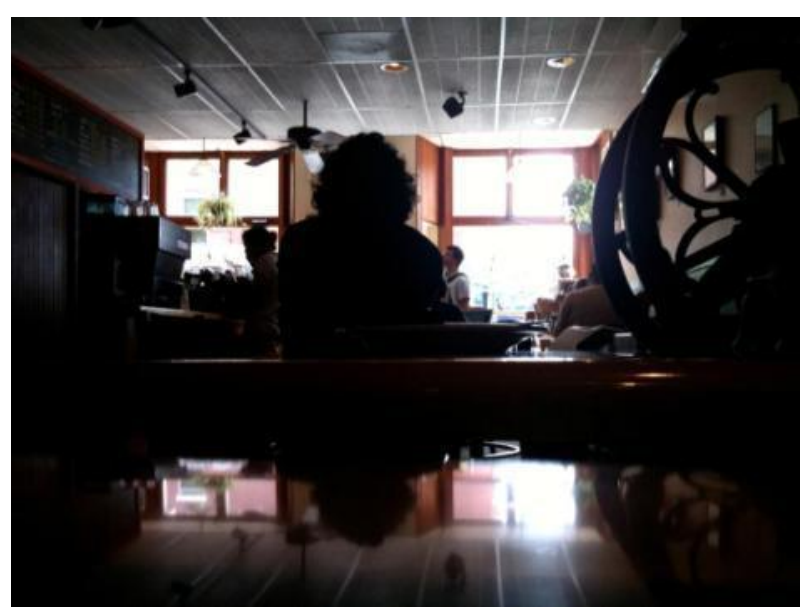

Figure 12. Inside 1369 Coffee House

\subsection{In what ways do independently-owned and chain-based coffee houses differ as third places?}

The differences between coffee houses as third places largely revolve around what they offer customers. Independently-owned coffee houses offer seating arrangements aimed at socializing, unique atmospheres, and novel décor, which is what Oldenburg (1989) found to be the best aspects of third places. In contrast, chain-based coffee houses give patrons free $\mathrm{Wi}-\mathrm{Fi}$, multiple power outlets, seating arrangements aimed at productivity, and media resources for local and national news. This is the opposite of a third place because these types of amenities are likely to impede sociability. Surprisingly, the data show that even though independent and chain cafés provide different conveniences, these do not necessarily hinder socialization or work activities.

\subsubsection{Sociability}

While coding field notes about independent coffee houses, an unexpected trend emerged: baristas and staff at independent cafés were not as friendly as those at Starbucks. For example, during two of the observations at the Central Square Starbucks, baristas greeted patrons by name. They also knew regulars' orders and chatted about current events and shared experiences while preparing food and beverages. Observations also detail how baristas treated customers who were undecided about what to order. The Starbucks baristas would help customers by explaining the many options available and even offering suggestions. In contrast, the baristas at the independently-owned coffee houses were more aloof and would just wait or sometimes stare at a customer, offering minimal assistance.

\subsubsection{Seating and Activities}

Both independent and chain coffee houses offered close seating arrangements that fostered socializing. For example, at the Central Square Starbucks the tables and chairs were too small for computers, and the seating was too cramped for working. This type of crammed environment forced sociability because individuals really had no other option but to speak to each other. There were many instances of socializing at Pavement because of the living room style design, but in each section many conversations took place usually between students and instructors from the local college or among other young adults.

Seating not only aided in the sociability of coffee houses, but also in productivity. The Starbucks in Copley Square had seating that was conducive for productivity that required portable electronic devices. This location had ample workspace in the form of tables and chairs, stand-alone bars, and individual cubbies that made for semi-private workstations (see Figure 10).

\subsubsection{Amenities}

Amenities emerged as a key distinguishing factor across cafés. We expected that independently-owned coffee houses would be in a losing competition with chain-based coffee houses because of the cost of providing various amenities such as Wi-Fi and power outlets, as well as media resources such as newspapers, televisions, and bulletin boards. As such, we used Starbucks as the reference group for coding amenities. In July 2010, Starbucks began offering free Wi-Fi at all locations, with no time limit and no membership fee. Like Starbucks, all three independent locations also offered Wi-Fi to customers, but most were fee-based or had time limits. Diesel Café and 1369 Coffee House had fee-based Wi-Fi services that charged by the hour, day, week, or month. Pavement offered four free hours of $\mathrm{Wi}-\mathrm{Fi}$, but had a poor Internet connection. Another amenity that was generally plentiful at Starbucks but more difficult to find at independent locations was power outlets for charging electronics, which made finding a seat near one a valuable commodity. These two amenities alone may be the 
leading reason that patrons have transitioned from using coffee shops as a space for social gathering to using them as spaces for work and productivity. With the freedom to work anywhere with Internet access, it is no wonder that many have started visiting coffee houses to complete computing tasks in peace.

The third amenity that Starbucks offered at every location was media sources, specifically local and national newspapers. This was not the case, however, at the independently-owned cafés, none of which offered newspapers for sale. This is an interesting finding because previous research has concluded that one reason individuals patronize coffee houses is to hear the latest news and gossip (Cowan, 2004).

\subsubsection{Atmosphere}

Oldenburg (1989) asserts that novelty is important to coffee houses because it provides patrons with a fresh setting to revive themselves. Examining the photographs taken from the six coffee houses gives insight into the different décor and design themes at independently-owned coffee houses, which often stand in stark contrast to the branded décor of Starbucks. Each independently-owned coffee house was unique in appearance and atmosphere. For example, the décor at Pavement was delicate and airy with brick walls painted white, which lightened the atmosphere of the café. Chandeliers dangled above the tables to further illuminate the café and added a touch of elegance. Diesel Café had a bicycle theme, reflecting its location in a community of cycling enthusiasts. It had vibrant red walls with street signs and bicycle parts as decorations. 1369 Coffee House looked like a grandmother's old Victorian home with wainscoting on the walls, a weathered wooden floor, and small windows throughout the space. In contrast, the Starbucks locations were always neutral in appearance and color scheme. Two of the three Starbucks had brick accent walls, which were bordered with light brown walls, dark brown ceilings, and a wall of windows facing out to the street. The Starbucks in Central Square had two walls with large window paneling and a third wall painted an off-white hue. A shelving unit, holding merchandise, covered a whole wall in all three locations; in all locations this was a lightly stained wooden bookshelf stocked with coffee, mugs, and brewing equipment.

\section{Discussion}

Coffee houses have been celebrated as "third places" that serve as alternatives to home and work, as well as environments that promote social support, friendship, and community (Oldenburg, 1989). Yet coffee houses have experienced a great deal of change in recent years. Since Oldenburg's work began over 20 years ago, portable technology has advanced tremendously and gained popularity. Desktop computers are no longer the norm and mobile phones, laptops, and tablets are now widely accessible. The advent of and access to portable technology has significantly extended the range of activities that patrons of coffee houses can undertake. In addition, the transition from locally and independently-owned coffee houses to those that are chain-based has been widely documented by urban researchers who lament how chain-based businesses care less about the interests of their communities (Clark, 2007; Porter, 1995; Thompson \& Arsel 2004). This paper qualitatively addresses these two transformations using the concept of the third place with two major findings.

First, though Oldenburg (1989) champions the coffee house as a third place where people primarily socialize, we find that the rise of portable devices has transformed the activities found in coffee houses, for better or worse. We classified all coffee houses as either social, multifunctional, or non-social spaces. Surprisingly, the majority of coffee houses were multifunctional spaces, where people both socialize and use electronic devices. In multifunctional third places, technology and productivity occur, often seamlessly and without conflict, alongside socializing and conversation. Although Oldenburg has referred to this type of multifunctional space as a "hostile habitat" that harms the sociability of individuals by offering activities that detract from conversation, our observations of patrons at Pavement, Diesel, and the Davis Square and Copley Square Starbucks locations conclude that those who come there to socialized do not seem to mind the patrons who are there to work.

The Central Square Starbucks was the only social space where patrons did not utilize personal electronic devices. Patrons used this coffee house to converse with friends, co-workers, and classmates without the added duty and stress of playing host in their own homes. This café best captured Oldenburg's original conceptualization of a third place. On occasion, people worked on computers at this café, but they did not seem disturbed by the overwhelming majority of patrons who were there for social purposes. 1369 Coffee House, the only non-social space, was the antithesis of a third place despite its self-proclamation as such on its website. The cramped quarters and 30-minute loitering limit largely contributed to its lack of socializing. Although at first glance the fee-based Wi-Fi would seem to deter productivity, the few patrons in the coffee house were mostly working on laptops and other devices.

The inclusion of observations from both independent and chain-based coffee houses illuminates the similarities and differences between these types of establishments as third places as they differed in seating, Internet 
connections, power outlets, uniqueness, and social atmosphere. Amenities, ample seating, and spatial arrangement are highly conducive to attracting customers to come in and stay for long periods of time. In such environments, people can complete a variety of tasks at a relatively low cost and with no time limitations. In general, Starbucks provided customers with conveniences geared towards productivity, such as power outlets, $\mathrm{Wi}-\mathrm{Fi}$, and media resources while independently-owned coffee houses offered amenities that encourage conversing with others, like seating arrangements designed for socializing, enjoying a novel atmosphere, and uniqueness.

Starbucks offered the benefits of an office: power for electronics, large working surfaces, and free, unlimited Internet access. It created a pleasant, non-isolated work environment to complete tasks for jobs, school, or social networking with its neutral décor and soft, unobtrusive music. In addition, Starbucks was able to offer this core of amenities at most locations; this reliable standardization is part of its allure. The work environment created by technology-supporting amenities at Starbucks may benefit the growing customer base that desires to use portable technology to work anywhere. But Starbucks locations can serve multiple purposes for customers. They can be places for comfortable leisure in the form of reading (e.g., The New York Times, USA Today, and The Wall Street Journal were all sold there) as well as socializing with friends.

Independent coffee houses offered local flavor that Starbucks does not. They catered to their home neighborhood in part because they are not restricted by stringent branding rules. This allows patrons to feel more comfortable and at home, with the presence of locally-made furniture, art, and even photography. In addition, specially designed seating allowed many people to sit together and encouraged conversation. However, independent cafés were largely characterized by limitations placed on customer productivity in the form of time restrictions, lack of workspace and outlets, and fees for Wi-Fi. All of these presented barriers to attracting customers and meeting their needs in a modern, connected culture. But despite fewer technology-supporting amenities, productivity is not impossible at these locations.

\subsection{Directions for Future Research}

Unobtrusive observation is a useful tool for collecting data regarding the way that individuals use a particular space and their interactions inside that space. Unfortunately, researchers are not able to see or document everything that happens during a visit. The coffee houses in which the data were collected are large establishments, some with more than one room or section, making it impossible to record everything as it happens. Further research could utilize in-depth interviews or surveys of café patrons, along with employees and owners to more fully understand why people visit coffee houses. For instance, just because a patron is on the computer does not mean that he or she is completing work for pay.

There are a large number of coffee houses in Boston and we used purposive sampling and preliminary observations to select only a small number. Future work should investigate a larger number of coffee houses and in a broader number of cities. A more diverse data set may clarify the debate between which coffee house is better for the community--chain-based or independently-owned--as well as add to the literature on coffee houses as third places. A related limitation is that many patrons in our coffee houses were traditional university students, as Boston functions as a large college town in some ways. With this population included in the sample, it seems more likely that there would be a larger group of people in the coffee houses for work-related means. Future research should include cafés that cater to fewer students and university staff. A larger and more diverse sample may produce different patterns of activities and varying levels of sociability at both independent and chain-based coffee shops or it may provide even more evidence of a work-based culture in coffee houses across the board.

\section{References}

Bazelon, E. (2009, June 2). The self-employed depression. The New York Times. p. MM38.

Blank, G., \& Van Vooren, N. (2007). Camping out in the coffee shop world: A sociological analysis of coffee shop conventions. Paper presented at the annual meeting of the American Sociological Association, August 11-14, 2007, New York, New York.

Chadios, K. (2005). The urban coffee shop.. (Master's Thesis). Department of Architecture, Massachusetts Institute of Technology, Cambridge, MA. http://hdl.handle.net/1721.1/33031

Clark,T. (2007). Starbucked: A double tall tale of caffeine, commerce, and culture. New York, NY: Little, Brown and Company.

Corbin, J., \& Strauss, A. L. (2008). Basics of qualitative research. Thousand Oaks, CA: Sage.

Cowan, B. (2004). The rise of the coffeehouse reconsidered. The Historical Journal, 47, 21-46. http://dx.doi.org/10.1017/S0018246X03003492 
Emerson, R. M. (1981). Observational field work. American Review of Sociology, 7, $351-378$. http://dx.doi.org/10.1146/annurev.so.07.080181.002031

Friedman, M. (2010). Grassroots groups confront the corporation: Contemporary strategies in historical perspectives. Journal of Social Issues, 50, 153-167. http://dx.doi.org/10.1111/j.1540-4560.1996.tb01367.x

Giorgi, A. (1997). The theory, practice, and evaluation of the phenomenological method as a qualitative research $\begin{array}{lllll}\text { procedure. Journal of } & \text { Phenomenological } & \text { Psychology, } & \text { 28, }\end{array}$ http://dx.doi.org/10.1163/156916297X00103

Goffman, E. (1959). The presentation of self in everyday life. Garden City, NY: Anchor Books.

Goffman, E. (1963). Behavior in public places: Notes on the social organization of gatherings. New York, NY: The Free Press.

Goffman, E. (1971). Relations in public: Microstudies on the public order. New York, NY: Basic Books, Inc.

Hammersley, M. (1987). Some notes on the terms 'validity' and 'reliability. British Educational Research Journal, 13, 73-81. http://dx.doi.org/10.1080/0141192870130107

Hampton, K. N., \& Gupta, N. (2008). Community and social interaction in the wireless city: Wi-Fi use in public and semi-public spaces. New Media and Society, 10, 831-850. http://dx.doi.org/10.1177/1461444808096247

Heffernan, V. (2011, February 13). Table disservice. The New York Times, p. MM22.

Lee, R. (2007, March 1). As coffee houses get noisier, freelancers seek alternative work spaces. Retrieved from http://abcnews.go.com/Business/SmallBiz/story?id=2915913page=1\#.Ua9M2EDVB8F

Lindesmith, A. R., Strauss, A. L., \& Denzin, N. K. (1975). Social psychology. Englewood Cliffs, NJ: Prentice Hall.

Lofland, L. H. (1973). A world of strangers: Order and action in urban public space. Prospect Heights, IL: Waveland Press, Inc.

Mohr, L. A., Webb, D. J., \& Harris, K. E. (2001). Do consumers expect companies to be socially responsible? The impact of corporate social responsibility on buying behavior. The Journal of Consumer Affairs, 35, 45-72. http://dx.doi.org/10.1111/j.1745-6606.2001.tb00102.x

Oldenburg, R. (1989). The great good place: Cafés, coffee shops, bookstores, bars, hair salons and other hangouts at the heart of a community. Boston, MA: Paragon House.

Oldenburg, R. (2001). Celebrating the third place: Inspiring stories about the "great good places" at the heart of our communities. New York, NY: Marlowe and Company.

Pendergrast, M. (1999). Uncommon grounds. New York, NY: Basic Books.

Pincus, S. (1995). Coffee politicians does create: Coffeehouses and restoration political culture. The Journal of Modern History, 31, 807-834. http://dx.doi.org/10.1086/245229

Porter, M. E. (1995, May 1). The competitive advantage of the inner city. Harvard Business Review, 73(3), 55-71.

PRWeb. (2010). Survey shows Bostonians would sooner cut Tom Brady's hair or rat out Whitey Bulger than give up their coffee. Retrieved June 1, 2013 from http://www.prweb.com/pdfdownload/4653534.pdf

Roseberry, W. (1996). The rise of yuppie coffees and the reimagination of class in the United States. American Anthropologist, 98, 762-775. http://dx.doi.org/10.1525/aa.1996.98.4.02a00070

Strauss, A., \& Corbin, J. (1990). Basics of qualitative research: Grounded theory procedures and techniques. Newbury Park, CA: Sage Publications, Inc.

Thompson, C. J., \& Arsel, Z. (2004). The Starbucks brandscape and consumers' (anticorporate) experiences of glocalization. Journal of Consumer Research, 31, 631-642. http://dx.doi.org/10.1086/425098

Waxman, L. (2006). The coffee shop: Social and physical factors influencing place attachment. Journal of Interior Design, 31, 35-53. http://dx.doi.org/10.1111/j.1939-1668.2006.tb00530.x

Whyte, W. (1988). City: Rediscovering the center. New York, NY: Doubleday.

Zukin, S. (2010). Naked city: The death and life of authentic urban places. New York, NY: Oxford University Press.

\section{(cc) $\mathrm{Br}$}

This work is licensed under a Creative Commons Attribution 3.0 License. 